\title{
Single and Multiple Suicide Attempts: Prevalence and Correlates in School-Going Adolescents in Liberia in 2017
}

This article was published in the following Dove Press journal: Psychology Research and Behavior Management

\author{
Supa Pengpid (iD) 1,2 \\ Karl Peltzer $\mathbb{D}^{3}$
}

'ASEAN Institute for Health Development, Mahidol University, Nakhon Pathom, Thailand; ${ }^{2}$ Department of Research Administration and Development, University of Limpopo, Turfloop, South Africa; ${ }^{3}$ Department of Psychology, University of the Free State, Bloemfontein, South Africa
Correspondence: Karl Peltzer Department of Psychology, University of the Free State, Bloemfontein, South Africa

Email kfpeltzer@gmail.com
Background: This investigation aimed to estimate the prevalence and correlates of single and multiple suicide attempts among adolescents in Liberia.

Methods: Cross-sectional nationally representative data were analysed from 2744 adolescents (18 years of median age) who participated in the "2017 Liberia Global School-Based Student Health Survey (GSHS)".

Results: Results indicate that $33.7 \%$ of students had made a suicide attempt in the past 12 months (16.5\% single and 17.2\% multiple suicide attempts). In adjusted multinomial logistic regression analysis, having no close friends, loneliness, having been frequently physically attacked, ever used amphetamine and fast food intake were associated with multiple suicide attempts in the past 12 months. In addition, having been frequently in a physical fight and current tobacco use were associated with single suicide attempt. In sex stratified analyses, in addition, among boys frequent bullying victimization and among girls, parental tobacco use and parents never or rarely check on home work were associated with multiple suicide attempts. Multiple psychosocial distressors, multiple social-environmental factors, and multiple health risk behaviours were associated with single and multiple suicide attempts.

Conclusion: One in three students had made suicide attempt in the past 12 months (one in six students multiple suicide attempts) and several associated variables were detected which can aid in designing intervention strategies.

Keywords: suicide attempt, risk factors, protective factors, adolescents, Liberia

\section{Background}

Suicide is one of the major causes of death in young people. ${ }^{1}$ Attempting suicide is an important factor that can lead to suicide death. ${ }^{2}$ Programmes geared towards preventing suicide among adolescents need to be aware of the current trends of suicide attempts and its correlates. ${ }^{3}$ In a multicountry school survey including adolescents, the pooled prevalence of past 12 months attempted suicide in 8 countries of the sub-Saharan African region was $19.3 \%$, ranging from $10.2 \%$ in Tanzania to $27.9 \%$ in Benin. ${ }^{4}$ In a national household survey among adults in Liberia in 2008,

One in three respondents had participated in fighting forces and one in three of these were women, $44 \%$ had PTSD symptoms, $40 \%$ met the criteria for major depressive disorder, $11 \%$ reported suicidal ideation, $8 \%$ social dysfunction, and $6 \%$ attempted suicide. $^{5}$ 
"War exposure and post-conflict sexual violence, poverty, infectious disease, and parental death negatively impacted youth mental health in Liberia."6 Key informants perceived that among adolescents/young adults in Liberia, suicidal ideation was ranked fourth highest emotional and behavioural problem, after alcohol, drug use and delinquent behaviour. ${ }^{6}$

Conflict and post-conflict situations can be particularly stressful for children and adolescents facing the traumatising impact of direct exposure to violence as well as stressful living conditions. ${ }^{7}$

There is a lack of systematic data about suicidal behaviour among adolescents in Liberia. ${ }^{7}$ As previously reviewed in Pengpid and Peltzer, ${ }^{8}$ risk factors of suicide attempt may include

female sex, older age, lower socioeconomic status, having no close friends, loneliness, anxiety, bullied, exposure to interpersonal violence, alcohol use, drug use, cannabis use and injury.

In addition, recent large studies among adolescents showed that fast food consumption, soft drink intake, and sexual behaviour increased the likelihood of suicide attempts. $^{9-11}$ Studies on multiple suicide attempts found that lower social support, suicidal ideation, mental disorder, anxiety disorder, hopelessness, and family suicide history predicted multiple suicide attempts. ${ }^{12-14}$ Moreover, several studies ${ }^{15-17}$ showed a strong association between multiple adverse experiences and suicide attempts. It was hypothesised that sociodemographic factors, psychosocial distress, social-environmental factors, and health risk behaviours were associated with suicide attempts. The investigation aimed to estimate the prevalence and associated factors of single and multiple suicide attempts among school-going adolescents in Liberia.

\section{Methods}

Cross-sectional nationally representative data from the "2017 Liberia GSHS" were analyzed. ${ }^{18}$ More details on the survey methodology and the data can be accessed; ${ }^{18}$ "the overall response rate was $71 \%$."18

\section{Measures}

Outcome variable: Suicide attempt was assessed with the question, "During the past 12 months, how many times did you actually attempt suicide?" (number of times)
Responses were grouped into $1=0$ time, $2=1$ time, and $3=2$ or more times. ${ }^{18}$

Covariates included demographic variables (age, sex, and school grade), six psychosocial distress variables, seven social-environmental indicators, and eight health risk behaviours. The selection of covariates was based on previous literature review. $^{8-17}$

Psychosocial distress variables included 1) having no close friends, 2) mostly or always felt lonely in the past 12 months, 3) mostly or always been worried about something that could not sleep in the past 12 months, 4) three or more days being bullied in the past 30 days, 5) two or more times physically attacked in the past 12 months, and 6) two or more times being in a physical fight in the past 12 months. $^{18}$

Social-environmental indicators ${ }^{18}$ consisted of 1) mostly or always go hungry because of no food at home in the past 30 days, 2) never or rarely most school students were kind and helpful in the past 30 days, 3) parents or guardians never or rarely check on home work, 4) parents or guardians mostly or always go through your things without your approval, 5) parental tobacco use, 6) one or more days missing classes or school without permission in the past 30 days, and 7) emotional neglect was defined as rarely or never

parental or guardian understanding of your problems and worries? OR rarely or never parents or guardians really know what you were doing with your free time when you were not at school or work ${ }^{19}$

Health risk behaviours included 1) current tobacco use, 2) one or more times got into trouble as a result of drinking alcohol, 3) current cannabis use, 4) ever used amphetamines, 5) intake of two or more softs drinks a day, 6) having fast food on two or more days in the past seven days, 7) ever had sexual intercourse with two or more people, and 8) had two or more times a serious physical injury in the past 12 months. $^{18}$

\section{Data Analysis}

Statistical analyses were done with "STATA software version 15.0 (Stata Corporation, College Station, Texas, USA)." Adjusted multinomial logistic regression was used to assess predictors of single and multiple suicide attempts (past 12 months), with no past 12-month suicide attempt as reference category. The missing values were not included in the analysis. $\mathrm{P}<0.05$ was accepted as significant. 


\section{Results}

The sample comprised 2744 school adolescents (18 years median age, 2 years interquartile range), $48.2 \%$ were female and $51.8 \%$ male. One in three of the participants $(33.7 \%)$ had made a suicide attempt in the past year (16.5\% single and $17.2 \%$ multiple suicide attempts). Further sample details are shown in Table 1.

\section{Associations with Single and Multiple Suicide Attempts by Single Adverse Events}

In adjusted multinomial logistic regression analysis, having no close friends, loneliness, having been frequently physically attacked, ever used amphetamine, and fast food intake were associated with multiple suicide attempts in the past 12 months. In addition, having been frequently in a physical fight and current tobacco use were associated with a single suicide attempt (see Table 2). In sex stratified analyses, in addition, among boys frequent bullying victimization (OR: 2.19, CI: 1.19-4.02) and among girls, parental tobacco use (OR: 5.44, CI: 1.94, 15.26) and parents never or rarely check on home work (OR: 2.78, CI: 1.19, 6.51) were associated with multiple suicide attempts in the past 12 months.

\section{Associations with Single and Multiple Suicide Attempts by Multiple Adverse Events}

In the adjusted multinomial logistic regression analysis, compared to students who did not experience any psychosocial distress, students with 1, 2 and 3 or more psychosocial distress had an increased likelihood of single and multiple suicide attempts. Multiple social-environmental factors and multiple health risk behaviours were associated with single and multiple suicide attempts. The associations with multiple suicide attempts were stronger than with a single suicide attempt (see Table 3).

\section{Discussion}

The investigation aimed to estimate the prevalence and correlates of single and multiple suicide attempts in school adolescents in Liberia. The prevalence of past 12-month suicide attempts (33.7\%) in this study was much higher than in 8 countries of the sub-Saharan Africa region $(19.3 \%){ }^{4}$ It is possible that the postconflict situation in Liberia contributes to the high rate of suicide attempts among adolescents. ${ }^{5-7}$ Borba et $\mathrm{al}^{6}$ note that
Table I Sample and Attempted Suicide Characteristics Among School Adolescents in Liberia, 2017

\begin{tabular}{|c|c|c|c|}
\hline \multirow[t]{3}{*}{ Variables } & \multirow[t]{2}{*}{ Sample } & \multicolumn{2}{|c|}{$\begin{array}{l}\text { Suicide } \\
\text { Attempt (Past } \\
\text { I } 2 \text { Months) }\end{array}$} \\
\hline & & $\begin{array}{l}\text { I } \\
\text { Time }\end{array}$ & $\begin{array}{l}\geq 2 \\
\text { Times }\end{array}$ \\
\hline & $\mathbf{N}(\%)$ & $\%$ & $\%$ \\
\hline \multicolumn{4}{|l|}{ Socio-demographics } \\
\hline All & 2744 & 16.5 & 17.2 \\
\hline $\begin{array}{l}\text { Age (years) } \\
\quad \leq 14 \\
15-17 \\
\geq 18\end{array}$ & $\begin{array}{l}392(16.1) \\
932(36.3) \\
1337(47.6)\end{array}$ & $\begin{array}{l}12.8 \\
16.3 \\
18.2\end{array}$ & $\begin{array}{l}12.1 \\
14.7 \\
20.4\end{array}$ \\
\hline $\begin{array}{l}\text { Gender } \\
\text { Female } \\
\text { Male }\end{array}$ & $\begin{array}{l}1253(48.2) \\
1382(51.8)\end{array}$ & $\begin{array}{l}16.9 \\
15.9\end{array}$ & $\begin{array}{l}16.0 \\
17.8\end{array}$ \\
\hline \multicolumn{4}{|l|}{ Psychosocial distress } \\
\hline No close friends & $330(12.6)$ & 16.8 & 17.9 \\
\hline Loneliness & $367(13.9)$ & 19.3 & 26.7 \\
\hline Anxiety & $540(20.0)$ & 17.3 & 26.2 \\
\hline Frequently bullied ( $\geq 3$ days/month) & $528(22.5)$ & 19.7 & 34.1 \\
\hline $\begin{array}{l}\text { Frequently physically attacked } \\
(\geq 2 \text { times) }\end{array}$ & 1010 & 17.5 & 25.6 \\
\hline $\begin{array}{l}\text { Frequently in physical fight ( } \geq 2 \\
\text { times) }\end{array}$ & $629(23.8)$ & 19.7 & 32.6 \\
\hline \multicolumn{4}{|l|}{ Social-environmental factors } \\
\hline Mostly/always feeling hungry & $439(16.6)$ & 17.7 & 25.2 \\
\hline Low peer support & $571(24.6)$ & 21.4 & 18.3 \\
\hline Parental emotional neglect & $865(38.3)$ & 16.7 & 18.2 \\
\hline $\begin{array}{l}\text { Parents never/rarely check } \\
\text { home work }\end{array}$ & $734(29.8)$ & 17.0 & 18.9 \\
\hline $\begin{array}{l}\text { Parents mostly/always go } \\
\text { through things }\end{array}$ & $482(19.8)$ & 19.9 & 19.0 \\
\hline Parental tobacco use & $358(13.9)$ & 22.0 & 35.3 \\
\hline School truancy ( $\geq 3$ days/month) & $348(15.0)$ & 16.9 & 24.5 \\
\hline \multicolumn{4}{|l|}{ Health risk behaviours } \\
\hline Current tobacco use & $414(16.9)$ & 27.2 & 44.5 \\
\hline Trouble from alcohol use & $358(15.6)$ & 23.1 & 34.9 \\
\hline Current cannabis use & $193(8.4)$ & 25.2 & 42.6 \\
\hline Ever amphetamines & $180(7.9)$ & 22.9 & 52.4 \\
\hline Soft drink intake ( $\geq 2$ times/day) & $512(19.2)$ & 22.2 & 31.0 \\
\hline Fast food intake ( $\geq 2$ days/week) & $607(23.6)$ & 20.0 & 26.1 \\
\hline Multiple sexual partners $(\geq 2)$ & $684(27.8)$ & 19.6 & 21.7 \\
\hline Multiple injuries $(\geq 2)$ & 901 (39.7) & 14.9 & 24.6 \\
\hline
\end{tabular}

the most significant mental health needs for children, adolescents, and young adults included both externalizing and internalizing (i.e., lack of motivation, sadness/depression, suicidal thoughts, hopelessness) symptoms and behaviours. 
Table 2 Associations with Single and Multiple Suicide Attempts in the Past 12 Months by Single Adverse Events

\begin{tabular}{|c|c|c|}
\hline \multirow[t]{2}{*}{ Variables } & $\begin{array}{l}\text { Single Suicide } \\
\text { Attempt }\end{array}$ & $\begin{array}{l}\text { Multiple Suicide } \\
\text { Attempts }\end{array}$ \\
\hline & $\operatorname{ARRR}(95 \% \mathrm{Cl})$ & $\operatorname{ARRR}(95 \% \mathrm{Cl})$ \\
\hline \multicolumn{3}{|l|}{ Socio-demographics } \\
\hline \multicolumn{3}{|l|}{ Age (years) } \\
\hline$\leq 14$ & I (Reference) & I (Reference) \\
\hline $15-17$ & $1.76(0.86,3.59)$ & $2.21(0.99,3.98)$ \\
\hline$\geq 18$ & $1.52(0.66,3.49)$ & $2.16(0.91,5.09)$ \\
\hline \multicolumn{3}{|l|}{ Gender } \\
\hline Female & I (Reference) & I (Reference) \\
\hline Male & $0.97(0.62,1.50)$ & $1.36(0.85,2.17)$ \\
\hline \multicolumn{3}{|l|}{ Psychosocial distress } \\
\hline No close friends & $1.21(0.57,2.60)$ & $2.63(1.48,4.68)^{* * *}$ \\
\hline Loneliness & $1.82(0.97,3.42)$ & $1.96(1.15,3.37)^{*}$ \\
\hline Anxiety & $1.13(0.69,1.85)$ & $1.47(0.83,2.59)$ \\
\hline $\begin{array}{l}\text { Frequently bullied ( } \geq 3 \text { days/ } \\
\text { month) }\end{array}$ & $1.14(0.63,2.08)$ & $1.45(0.85,2.47)$ \\
\hline $\begin{array}{l}\text { Frequently physically attacked } \\
\text { ( } \geq 2 \text { times/year) }\end{array}$ & $1.01(0.69,1.47)$ & $2.42(1.38,4.25)^{* *}$ \\
\hline $\begin{array}{l}\text { Frequently in physical fight } \\
\text { ( } \geq 2 \text { times/year) }\end{array}$ & $2.20(1.37,3.53)^{* * * *}$ & $1.76(0.93,3.32)$ \\
\hline \multicolumn{3}{|l|}{$\begin{array}{l}\text { Social-environmental } \\
\text { factors }\end{array}$} \\
\hline Mostly/always feeling hungry & $1.25(0.67,2.35)$ & $1.06(0.54,2.09)$ \\
\hline Low peer support & $1.63(0.97,2.74)$ & $1.36(0.74,2.50)$ \\
\hline Parental emotional neglect & $0.99(0.58,1.70)$ & $1.02(0.54,1.92)$ \\
\hline $\begin{array}{l}\text { Parents never/rarely check } \\
\text { home work }\end{array}$ & $0.97(0.59,1.58)$ & $0.89(0.49,1.64)$ \\
\hline $\begin{array}{l}\text { Parents mostly/always go } \\
\text { through things }\end{array}$ & $1.06(0.66,1.71)$ & $0.98(0.57,1.66)$ \\
\hline Parental tobacco use & $1.25(0.5 \mathrm{I}, 3.07)$ & $2.11(0.99,4.52)$ \\
\hline $\begin{array}{l}\text { School truancy ( } \geq 3 \text { days/ } \\
\text { month) }\end{array}$ & $0.76(0.39,1.48)$ & $0.69(0.28,1.70)$ \\
\hline \multicolumn{3}{|l|}{ Health risk behaviours } \\
\hline Current tobacco use & $2.04(1.02,4.04)^{*}$ & $1.18(0.5 \mathrm{I}, 2.77)$ \\
\hline Trouble from alcohol use & $1.27(0.69,2.35)$ & $1.30(0.66,2.58)$ \\
\hline Current cannabis use & $1.83(0.5 \mathrm{I}, 6.55)$ & $2.59(0.94,7.17)$ \\
\hline Ever amphetamines & $1.17(0.27,5.05)$ & $2.87(1.19,6.89)^{*}$ \\
\hline Soft drink intake ( $\geq 2 /$ day) & $1.07(0.62,1.85)$ & $1.14(0.61,2.11)$ \\
\hline Fast food intake ( $\geq 2 /$ week) & $1.72(1.03,2.87)^{*}$ & $1.93(1.11,3.34)^{*}$ \\
\hline $\begin{array}{l}\text { Multiple sexual partners } \\
\text { (lifetime) }\end{array}$ & $1.35(0.85,2.14)$ & $1.40(0.84,2.33)$ \\
\hline Multiple injuries (past year) & $0.70(0.38,1.29)$ & $1.09(0.65,1.83)$ \\
\hline
\end{tabular}

Notes: ***P<0.00I; **P<0.01; *P<0.05.

Abbreviations: ARRR, adjusted relative risk ratio; $\mathrm{Cl}$, confidence interval.

While these symptoms have been consistently documented in youth exposed to childhood adversity and exposure to traumatic experiences, these findings should be viewed in the context of the total breakdown of many protective communal, family, and societal structures. ${ }^{6}$
Table 3 Associations with Single and Multiple Suicide Attempts in the Past 12 Months by Multiple Adverse Events

\begin{tabular}{|c|c|c|c|}
\hline \multirow[t]{2}{*}{ Variables } & Prevalence & $\begin{array}{l}\text { Single Suicide } \\
\text { Attempt }\end{array}$ & $\begin{array}{l}\text { Multiple Suicide } \\
\text { Attempts }\end{array}$ \\
\hline & $\%$ & $\operatorname{ARRR}(95 \% \mathrm{CI})^{\mathrm{a}}$ & $\operatorname{ARRR}(95 \% \mathrm{CI})^{\mathrm{a}}$ \\
\hline \multicolumn{4}{|c|}{ No of psychosocial distresses } \\
\hline 0 & 32.0 & I (Reference) & I (Reference) \\
\hline I & 31.8 & $1.68(1.18,2.39)^{* *}$ & $3.79(2.26,6.35)^{* * *}$ \\
\hline 2 & 20.8 & $2.54(1.94,3.33)^{* * *}$ & $5.12(2.76,9.48)^{* * *}$ \\
\hline 3 or more & 15.5 & $2.55(1.58,4.12)^{* * *}$ & $14.02(8.70,22.58)^{* * *}$ \\
\hline \multicolumn{4}{|c|}{ No of social-environmental factors } \\
\hline 0 & 26.0 & I (Reference) & I (Reference) \\
\hline I & 29.0 & $1.32(0.86,2.02)$ & $1.14(0.80,1.64)$ \\
\hline 2 & 23.6 & $1.57(0.94,2.60)$ & $2.05(1.35,3.13)^{* * *}$ \\
\hline 3 or more & 20.4 & $2.11(1.38,3.24)^{* * *}$ & $2.68(1.80,4.01)^{* * *}$ \\
\hline \multicolumn{4}{|c|}{ No of health risk behaviours } \\
\hline 0 & 31.3 & I (Reference) & I (Reference) \\
\hline I & 35.3 & $1.03(0.66,1.60)$ & $1.61(0.99,2.62)$ \\
\hline 2 & 18.1 & $1.91(1.35,2.70)^{* * *}$ & $2.43(1.36,4.35)^{* *}$ \\
\hline 3 or more & 15.3 & $3.47(2.34,5.15)^{* * *}$ & $8.27(4.87,14.04)^{* * *}$ \\
\hline
\end{tabular}

Notes: $* * * \mathrm{P}<0.001 ; * * \mathrm{P}<0.01$; ${ }^{\mathrm{a}}$ Adjusted for age, sex and school grade.

Abbreviations: ARRR, adjusted relative risk ratio; $\mathrm{Cl}$, confidence interval.

Previous studies found a higher prevalence of suicide attempts (single and multiple) in girls than in boys, ${ }^{20,21}$ while no significant sex differences were found in this study. This result seems to show that boys "internalize emotional-behavioural problems (leading more likely to suicidal ideation and suicide attempts) ${ }^{, 22}$ similarly than girls do. In a multicountry school survey among adolescents study, ${ }^{20}$ suicide attempts increased with age, while age differences in the prevalence of single and multiple suicide attempts were not observed in this study. Unlike a previous study, ${ }^{20}$ this investigation did not find an association between low economic status (mostly feeling hungry) and suicide attempt.

In agreement with previous studies, ${ }^{20,21,23,24}$ this study found an association between loneliness, no close friends, bullying victimization, interpersonal violence and single and/or multiple suicide attempts. Several researchers ${ }^{13,14}$ emphasised the importance of mental disorder and/or hopelessness in predicting multiple suicide attempts. These findings suggest the importance of treating psychosocial distress and prevention of bullying victimization and interpersonal violence to prevent suicide.

In agreement with previous investigations, ${ }^{8,10,20,25}$ the findings of this research show an association between current tobacco use, drug use, parental tobacco use and 
fast food intake with single and/or multiple suicide attempts. Several mechanisms have been proposed ${ }^{10}$ for the link between fast food consumption and suicide attempts, for example,

fast food consumption may increase risk for suicide attempts by increasing vulnerability to traumatic stress via alterations in brain structure and function, with stress being a well-known predictor of suicide attempts in adolescents. $^{10,26}$

Some research ${ }^{9,11,27}$ showed an association between sexual behaviour, injury, soft drink intake and suicide attempt, while this study did not discover such links.

Only among girls, this study found an association between social-environmental factors (parental tobacco use and parents never/rarely check home work) and multiple suicide attempts, which concurs with some previous research. ${ }^{20,25}$ In agreement with former research, ${ }^{15-17}$ this study showed a strong association between multiple adverse experiences and single and multiple suicide attempts, and appeared to be stronger in multiple suicide attempts. This seems to confirm a dose-response relationship between the more adverse experiences, the more likely multiple suicide attempts are made.

Study limitations include that this investigation was limited because of its cross-sectional design, and the inclusion of only school adolescents. The questionnaire administered was by self-report, including suicidal behaviour, psychosocial distress, and health risk behaviours, and could have led to bias in reporting. Given that the information has not been validated, future research should validate these data. An additional limitation was that the GSHS in Liberia did not assess help-seeking behaviours for suicidal behaviours.

The manuscript is based on a self-report, and given information has not been validated. Thus, the authors should highlight this limitation and warn clearly about this possible bias. In addition, future research should validate these data.

\section{Conclusion}

The study found among school-going nationally representative adolescents in Liberia that one in three students had made a suicide attempt in the past 12 months (one in six students multiple suicide attempts). Several risk factors, including having no close friends, loneliness, having been frequently physically attacked, ever used amphetamine, fast food intake, having been frequently in a physical fight, current tobacco use, frequent bullying victimization, parental tobacco use and parents never or rarely check on home work were identified for both or one of the sexes for multiple and/or single suicide attempt, which can assist in guiding interventions to prevent suicidal behaviour in this adolescent school population.

\section{Abbreviations}

GSHS, Global School-Based Student Health Survey; STATA, statistics and data.

\section{Data Sharing Statement}

The data for the current study are publicly available at the World Health Organization NCD Microdata Repository (URL: https://extranet.who.int/ncdsmicrodata/index.php/ catalog).

\section{Ethics Approval and Consent to Participate}

The present study was based on an analysis of the Liberia 2017 GSHS survey dataset freely available online with all identifier information detached. The Liberia 2017 GSHS was approved by the Liberia Ministry of Education and the World Health Organization. Therefore, the permission and ethical approval for the present analysis was automatically deemed unnecessary. Moreover, during the GSHS survey, written assent attached to a questionnaire was obtained from all eligible participants before filling the questionnaire.

\section{Acknowledgment}

The data source, the World Health Organization NCD Microdata Repository (URL: https:/extranet.who.int/ncdsmi crodata/index.php/catalog), is hereby acknowledged.

\section{Author Contributions}

All authors made a significant contribution to the work reported, whether that is in the conception, study design, execution, acquisition of data, analysis and interpretation, or in all these areas; took part in drafting, revising or critically reviewing the article; gave final approval of the version to be published; have agreed on the journal to which the article has been submitted; and agree to be accountable for all aspects of the work.

\section{Disclosure}

The authors declare that they have no competing interests in this work. 


\section{References}

1. World Health Organization (WHO). Adolescent mental health; 2019. Available from: https://www.who.int/news-room/fact-sheets/detail/ adolescent-mental-health. Accessed January 10, 2020.

2. Bilsen J. Suicide and youth: risk factors. Front Psychiatry. 2018;9:540. doi:10.3389/fpsyt.2018.00540

3. Hawton K, Saunders KE, O'Connor RC. Self-harm and suicide in adolescents. Lancet. 2012;379(9834):2373-2382. doi:10.1016/ S0140-6736(12)60322-5

4. Uddin R, Burton NW, Maple M, Khan SR, Khan A. Suicidal ideation, suicide planning, and suicide attempts among adolescents in 59 low-income and middle-income countries: a population-based study. Lancet Child Adolesc Health. 2019;3(4):223-233. doi:10.1016/ S2352-4642(18)30403-6

5. Johnson K, Asher J, Rosborough S, et al. Association of combatant status and sexual violence with health and mental health outcomes in postconflict Liberia. JAMA. 2008;300(6):676-690. doi:10.1001/ jama.300.6.676

6. Borba CP, Ng LC, Stevenson A, et al. A mental health needs assessment of children and adolescents in post-conflict Liberia: results from a quantitative key-informant survey. Int J Cult Ment Health. 2016;9 (1):56-70. doi:10.1080/17542863.2015.1106569

7. Samuels F, Jones N, Hamad BA, Cooper J, Galappatti A Rebuilding adolescent girls' lives mental health and psychosocial support in conflict-affected Gaza, Liberia and Sri Lanka. London, UK: Overseas Development Institute; 2015. Available from: https:// www.odi.org/sites/odi.org.uk/files/odi-assets/publications-opinionfiles/9999.pdf. Accessed December 5, 2020.

8. Pengpid S, Peltzer K. Suicide attempt and associated factors among adolescents in five Southeast Asian countries in 2015. Crisis. 2020;1-8. doi:10.1027/0227-5910/a000642

9. Jacob L, Stubbs B, Koyanagi A. Consumption of carbonated soft drinks and suicide attempts among 105,061 adolescents aged 12-15 years from 6 high-income, 22 middle-income, and 4 low-income countries. Clin Nutr. 2020;39(3):886-892. doi:10.1016/j.clnu.2019.03.028

10. Jacob L, Stubbs B, Firth J, Smith L, Haro JM, Koyanagi A. Fast food consumption and suicide attempts among adolescents aged 12-15 years from 32 countries. J Affect Disord. 2020;266:63-70. doi:10.1016/j.jad.2020.01.130

11. Smith L, Jackson SE, Vancampfort D, et al. Sexual behavior and suicide attempts among adolescents aged $12-15$ years from 38 countries: a global perspective. Psychiatry Res. 2019;112564. doi:10.1016/j.psychres.2019.112564

12. Merchant C, Kramer A, Joe S, Venkataraman S, King CA. Predictors of multiple suicide attempts among suicidal black adolescents. Suicide Life Threat Behav. 2009;39(2):115-124. doi:10.1521/ suli.2009.39.2.115

13. Pagura J, Cox BJ, Sareen J, Enns MW. Factors associated with multiple versus single episode suicide attempts in the 1990-1992 and 2001-2003 United States national comorbidity surveys. J Nerv Ment Dis. 2008;196 (11):806-813. doi:10.1097/NMD.0b013e31818b6a77
14. Liu Y, Zhang J, Sun L. Who are likely to attempt suicide again? A comparative study between the first and multiple timers. Compr Psychiatry. 2017;78:54-60. doi:10.1016/j.comppsych.2017.07.007

15. Wan Y, Chen R, Ma S, et al. Associations of adverse childhood experiences and social support with self-injurious behaviour and suicidality in adolescents. $B r J$ Psychiatry. 2019;214(3):146-152. doi:10.1192/bjp.2018.263

16. Cluver L, Orkin M, Boyes ME, Sherr L. Child and adolescent suicide attempts, suicidal behavior, and adverse childhood experiences in South Africa: a prospective study. J Adolesc Health. 2015;57 (1):52-59. doi:10.1016/j.jadohealth.2015.03.001

17. Khan MMA, Rahman MM, Islam MR, Karim M, Hasan M, Jesmin SS. Suicidal behavior among school-going adolescents in Bangladesh: findings of the global school-based student health survey. Soc Psychiatry Psychiatr Epidemiol. 2020;55 (11):1491-1502. doi:10.1007/s00127-020-01867-z

18. World Health Organization (WHO). Global school-based student health survey (GSHS); 2019. Available from: https://www.who.int/ ncds/surveillance/gshs/en/. Accessed December 5, 2020.

19. World Health Organization (WHO). Adverse Childhood Experiences International Questionnaire (ACE-IQ) Guidance for Analysing ACE-IQ. Available from: https://www.who.int/violence_injury_pre vention/violence/activities/adverse_childhood_experiences/guidance_ for_analysing.pdf?ua=1. Accessed April 2, 2020.

20. Liu X, Huang Y, Liu Y. Prevalence, distribution, and associated factors of suicide attempts in young adolescents: school-based data from 40 low-income and middle-income countries. PLoS One. 2018;13(12):e0207823. doi:10.1371/journal.pone.0207823

21. Miranda-Mendizabal A, Castellví P, Parés-Badell O, et al. Gender differences in suicidal behavior in adolescents and young adults: systematic review and meta-analysis of longitudinal studies. Int $J$ Public Health. 2019;64(2):265-283. doi:10.1007/s00038-018-1196-1

22. Kaess M, Parzer P, Haffner J, et al. Explaining gender differences in non-fatal suicidal behaviour among adolescents: a population-based study. BMC Public Health. 2011;11:597. doi:10.1186/1471-2458-11-597

23. Tang JJ, Yu Y, Wilcox HC, et al. Global risks of suicidal behaviours and being bullied and their association in adolescents: school-based health survey in 83 countries. EClinicalMedicine. 2020;19:100253. doi:10.1016/j.eclinm.2019.100253

24. Sharma B, Nam EW, Kim HY, Kim JK. Factors associated with suicidal ideation and suicide attempt among school-going urban adolescents in Peru. Int $J$ Environ Res Public Health. 2015;12 (11):14842-14856. doi:10.3390/ijerph121114842

25. Carballo JJ, Llorente C, Kehrmann L, et al. Psychosocial risk factors for suicidality in children and adolescents. Eur Child Adolesc Psychiatry. 2019. doi:10.1007/s00787-018-01270-9

26. Lee J, Jang H, Kim J, Min S. Development of a suicide index model in general adolescents using the South Korea 2012-2016 national representative survey data. Sci Rep. 2019;9(1):1846. doi:10.1038/ s41598-019-38886-z

27. Davaasambuu S, Batbaatar S, Witte S, et al. Suicidal plans and attempts among adolescents in Mongolia. Crisis. 2017;38 (5):330-343. doi:10.1027/0227-5910/a000447
Psychology Research and Behavior Management

\section{Publish your work in this journal}

Psychology Research and Behavior Management is an international, peer-reviewed, open access journal focusing on the science of psychology and its application in behavior management to develop improved outcomes in the clinical, educational, sports and business arenas. Specific topics covered in the journal include: Neuroscience, memory and decision making; Behavior modification and management; Clinical applications; Business and sports performance management; Social and developmental studies; Animal studies. The manuscript management system is completely online and includes a very quick and fair peer-review system, which is all easy to use. Visit http://www. dovepress.com/testimonials.php to read real quotes from published authors. 